\title{
Collaborative ICT Research for Development in Latin America and the Caribbean
}

\author{
Ignacio Casas \\ Computer Science \\ Department, Pontificia \\ Universidad Católica de \\ Chile \\ 4860 V. Mackenna Av., \\ Macul, Santiago, Chile
}

\author{
Sergio F. Ochoa, José A. Pino \\ Computer Science \\ Department, Universidad de \\ Chile \\ 2120 B. Encalada, Santiago, \\ Chile
}

\author{
Jaime Puente \\ Microsoft Research \\ Connections. \\ 6750 N Andrews Av. \#400. \\ Fort Lauderdale, FL, USA
}

\begin{abstract}
With funding provided by Microsoft Research, the Inter-American Development Bank and selected universities from the region, the LACCIR Federation promotes collaborative research in ICT and computer science within Latin America and the Caribbean (LAC). The focus is on applications for social and economic needs that are common throughout the LAC region. LACCIR aims to generate leverage between research teams and validate and generalize the research outcomes and their transfer to the society at large. This scientific collaboration allows researchers to address common problems and opportunities for the region. Thus, regional scientific collaboration becomes a possible source of solutions for its own social and economic needs. This paper describes the LACCIR organization, its main activities and some selected on-going research initiatives.
\end{abstract}

\section{Introduction}

The competition for greater shares of the global economy has led governments around the world to think strategically about the economic and social significance of academic research and development. This is clear in Latin America and the Caribbean (LAC), where many government organizations are currently reviewing the mission, structure and funding of their higher education, research and innovation systems. Their focus is on developing human capital and advancing technology in order to develop "knowledge economies".

The capabilities provided by the Information and Communication Technologies (ICT) are critical to economic, educational, and social advancement, since ICT is considered a transversal area for several key disciplines, such as education, health, ecommerce, agri-business, manufacturing, energy and environment. Improving the capabilities in ICT research can help LAC countries to improve the opportunities to find solutions to their common problems. This objective has been acknowledged in the working agenda of the Organization of American States (OAS) [5, 6], which argues that the scientific and technological research on ICT is a critical element for the economic and social development of the LAC region. Higher education institutions must participate as partners with government and industry in nationally-balanced, socio-economic strategies to increase this research capability.

However, there is an evident lack of critical mass in ICT research within most LAC research institutions, which is illustrated by the scarce results the region has at a world-wide level. Moreover, very few private enterprises are involved in research and development, as compared to leading countries in Europe, Asia and USA. These issues place an urgent call for collaboration and partnership in the region.

With the objective of addressing this challenge, the Latin American and Caribbean Collaborative ICT Research (LACCIR) Federation was created in May 2007. This initiative provides LAC research institutions with a virtual collaborative environment to promote cross-country research, educational solutions, and technology transfer to the local economies [10]. This paper describes the LACCIR activities, the current outcomes and its expected contribution to the region.

In the next section we present various statistics about ICT research in the LAC region, together with collaboration indicators. It highlights the importance of promoting cross-country ICT research in the region. Section 3 presents the LACCIR organizational structure, its objectives and main activities. Section 4 introduces the collaboration research projects supported by LACCIR and some preliminary results. Section 5 presents and discusses the related work. Finally Section 6 presents the conclusions and the future work in this initiative.

\section{The Critical Mass Effect}

Although the LAC region has world class universities and top level researchers, its main 
weakness is the small size of its research teams, due to scarce resources devoted to research activities and little involvement of private enterprises. As an example we can mention that the best research universities in Chile have Computer Science departments that have between 10 to 22 active researchers. An equivalent department in the USA may have about 100 researchers. This reduced critical mass situation is worsened by a notorious lack of collaboration among research teams within the region.

Aiming to illustrate this assertion, we conducted a study that uses refereed publications from the ISI Web of Knowledge as a data source [3, 4], considering the 2000-2011 period. This study attempts to identify research contributions (in terms of number of papers indexed by ISI) from Computer Science and ICT institutions in the LAC region. Figure 1 depicts a preliminary result of this study, where "LAC" represents the total aggregated productivity of the LAC region. This figure shows that the number of LAC publications in Computer Science and ICT, is similar (quantitatively speaking) to the contributions from a single European country such as Spain. If we just consider the number of publications, the most productive LAC country is Brazil, which published a number of ISI articles similar to the number published by the rest of the LAC countries in the analyzed time period $[1,7]$.

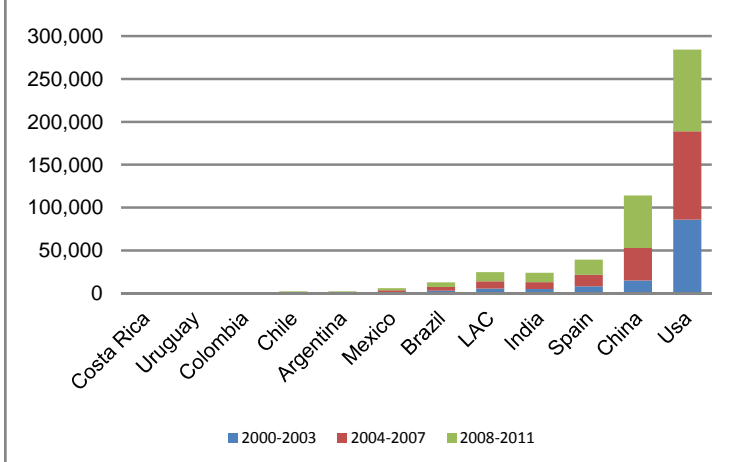

Figure 1. CS-ICT publications ISI per country/region in the period 2000-2011

The trend in computer science publications is similar to that observed in other research areas such as biomedical sciences, chemistry and physics. Table 1 shows the numbers of ISI publications in the 20002011 time span period for various knowledge areas including Computer Science and ICT.

Figure 2 shows the relative contribution, per LAC country, in terms of ISI publications. Brazil has the largest number of publications as well as the largest country population. It can be noticed that the Brazilian leadership (in terms of total production of ISI papers) occurs for publications in all the analyzed knowledge domains.

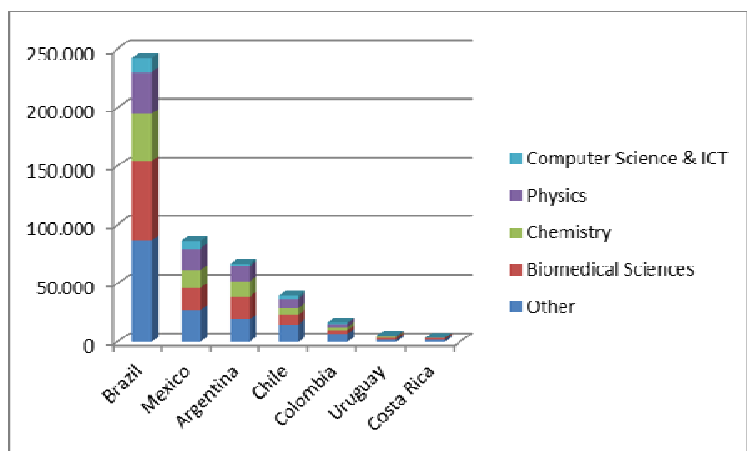

Figure 2. Relative contribution on ISI publications

Considering the total number of ISI publications in different knowledge areas (as shown in Table 1), Figure 3 depicts the relative research productivity per country, in terms of ISI publications per capita. The population count can be considered here as an independent variable. It can be seen in this figure that Argentina, Chile and Uruguay display a better production of scientific articles than Brazil, China and Mexico, but it is still much lower than Spain and USA $[1,7]$.

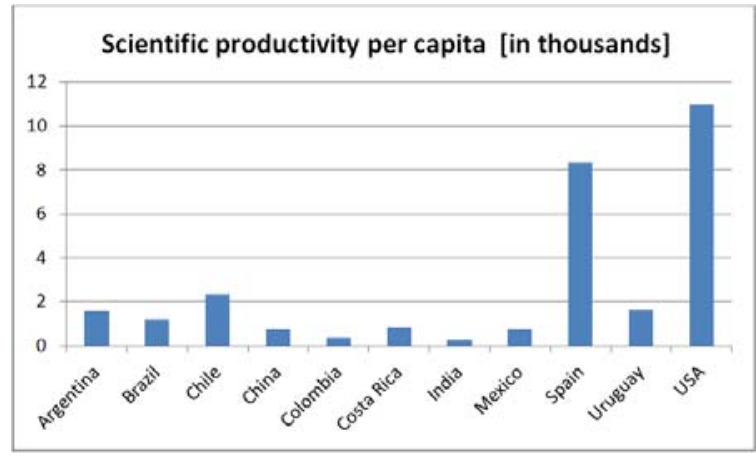

Figure 3. CS-ICT scientific productivity per country in the period 2000-2011

Now, we would like to "throw" into this analysis other variables such as "GDP per capita" and percentage of "GDP devoted to R\&D". These economic variables are very dependent on specific country policies and decision making towards science, technology and innovation. Figures 4 and 5 show these statistics $[11,12]$.

Table 1. ISI publications per country/region in the period 2000-2011 


\begin{tabular}{|c|c|c|c|c|c|c|}
\hline Country & $\begin{array}{l}\text { Year } \\
\text { Period }\end{array}$ & $\begin{array}{c}\text { Biomed. } \\
\text { Science }\end{array}$ & $\begin{array}{c}\text { Chemist } \\
\text { ry }\end{array}$ & Physics & $\begin{array}{c}\text { CS \& } \\
\text { ICT }\end{array}$ & Total \\
\hline \multirow{3}{*}{ Argentina } & $2000-2003$ & 5.695 & 4.022 & 3.931 & 521 & 18.318 \\
\hline & 2004-2007 & 6.259 & 4.177 & 4.147 & 644 & 20.896 \\
\hline & 2008-2011 & 7.560 & 5.281 & 4.500 & 1.007 & 27.589 \\
\hline \multirow{3}{*}{ Brazil } & 2000-2003 & 14.030 & 9.537 & 10.635 & 2.895 & 48.847 \\
\hline & 2004-2007 & 21.368 & 13.407 & 12.593 & 4.407 & 74.911 \\
\hline & 2008-2011 & 32.883 & 17.038 & 12.384 & 5.281 & 119.448 \\
\hline \multirow{3}{*}{ Chile } & 2000-2003 & 2.196 & 1.593 & 1.947 & 387 & 8.816 \\
\hline & 2004-2007 & 2.729 & 1.839 & 2.793 & 741 & 12.414 \\
\hline & 2008-2011 & 3.720 & 2.238 & 3.499 & 1.063 & 18.416 \\
\hline \multirow{3}{*}{ China } & $2000-2003$ & 26.074 & 50.632 & 33.119 & 14.880 & 151.107 \\
\hline & 2004-2007 & 56.726 & 105.771 & 60.639 & 37.808 & 307.355 \\
\hline & 2008-2011 & 114.302 & 172.930 & 91.912 & 61.319 & 515.638 \\
\hline \multirow{3}{*}{ Colombia } & $2000-2003$ & 609 & 446 & 608 & 85 & 2.748 \\
\hline & 2004-2007 & 838 & 640 & 744 & 165 & 4.113 \\
\hline & 2008-2011 & 1.683 & 1.404 & 1.250 & 531 & 9.343 \\
\hline \multirow{3}{*}{ Costa Rica } & 2000-2003 & 415 & 105 & 37 & 6 & 988 \\
\hline & 2004-2007 & 454 & 59 & 46 & 9 & 1.201 \\
\hline & 2008-2011 & 545 & 93 & 41 & 27 & 1.547 \\
\hline \multirow{3}{*}{ India } & $2000-2003$ & 16.766 & 24.405 & 14.572 & 4.834 & 74.197 \\
\hline & 2004-2007 & 24.816 & 37.589 & 19.655 & 8.033 & 105.716 \\
\hline & 2008-2011 & 38.966 & 52.121 & 26.411 & 10.903 & 156.164 \\
\hline \multirow{3}{*}{ LAC } & $2000-2003$ & 29.746 & 20.177 & 22.937 & 5.500 & 107.398 \\
\hline & 2004-2007 & 39.841 & 26.252 & 26.470 & 8.454 & 147.927 \\
\hline & 2008-2011 & 55.601 & 33.059 & 27.184 & 10.645 & 216.529 \\
\hline \multirow{3}{*}{ Mexico } & $2000-2003$ & 4.943 & 3.353 & 5.788 & 1.334 & 21.596 \\
\hline & 2004-2007 & 6.414 & 5.037 & 6.581 & 2.109 & 28.656 \\
\hline & 2008-2011 & 7.624 & 6.220 & 6.901 & 2.476 & 35.824 \\
\hline \multirow{3}{*}{ Spain } & $2000-2003$ & 26.173 & 23.290 & 15.860 & 8.046 & 96.210 \\
\hline & 2004-2007 & 31.861 & 28.710 & 20.649 & 13.358 & 125.289 \\
\hline & 2008-2011 & 41.188 & 33.142 & 24.746 & 17.840 & 167.582 \\
\hline \multirow{3}{*}{ Uruguay } & $2000-2003$ & 487 & 199 & 215 & 53 & 1.323 \\
\hline & 2004-2007 & 587 & 275 & 214 & 76 & 1.694 \\
\hline & 2008-2011 & 760 & 430 & 225 & 113 & 2.426 \\
\hline \multirow{3}{*}{ USA } & $2000-2003$ & 339.448 & 114.167 & 116.533 & 85.869 & 1.027 .197 \\
\hline & 2004-2007 & 373.946 & 131.496 & 132.709 & 103.078 & 1.144 .715 \\
\hline & 2008-2011 & 402.344 & 147.271 & 133.867 & 95.318 & 1.261 .557 \\
\hline
\end{tabular}

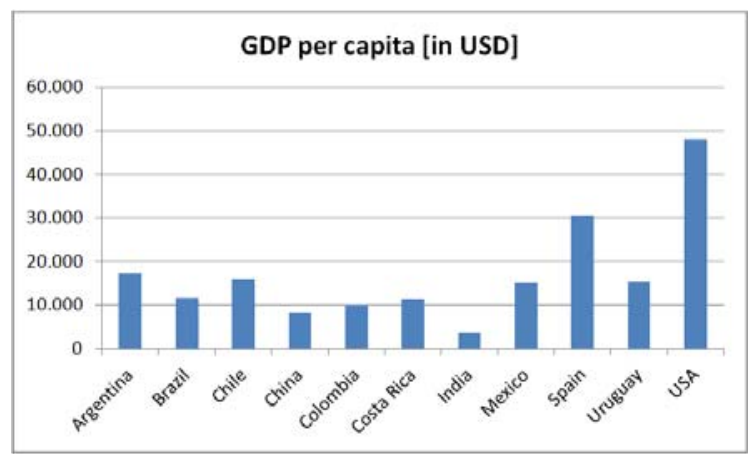

Figure 4. Gross Domestic Product per capita, 2011

We could we assume that with little increase in the research and development expenditures in the leading LAC countries, we could have an interesting effect on scientific productivity and development for the region? In LACCIR we believe it is so.

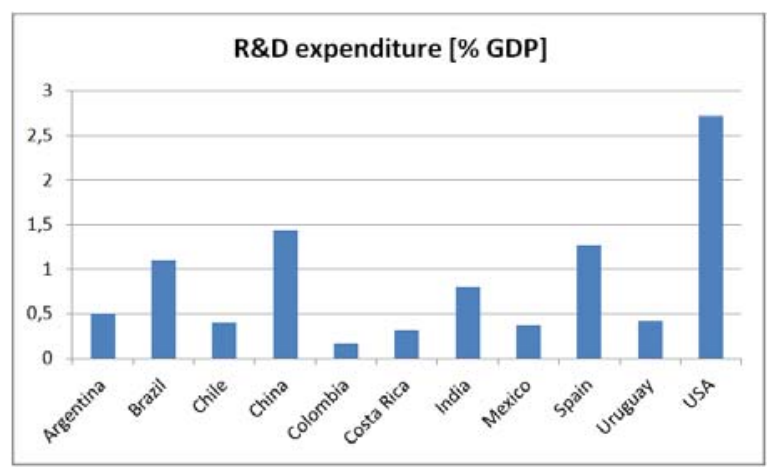

Figure 5. Percentage of GDP for R\&D, 2007

Following with the analysis, Figure 6 depicts the amount of "international collaboration" in Computer Science and ICT research by considering again just ISI papers during the 2000-2011 period. We define international collaboration as the number of ISI papers that were written by researchers from at least two different countries world-wide, with the participation of at least one LAC researcher.

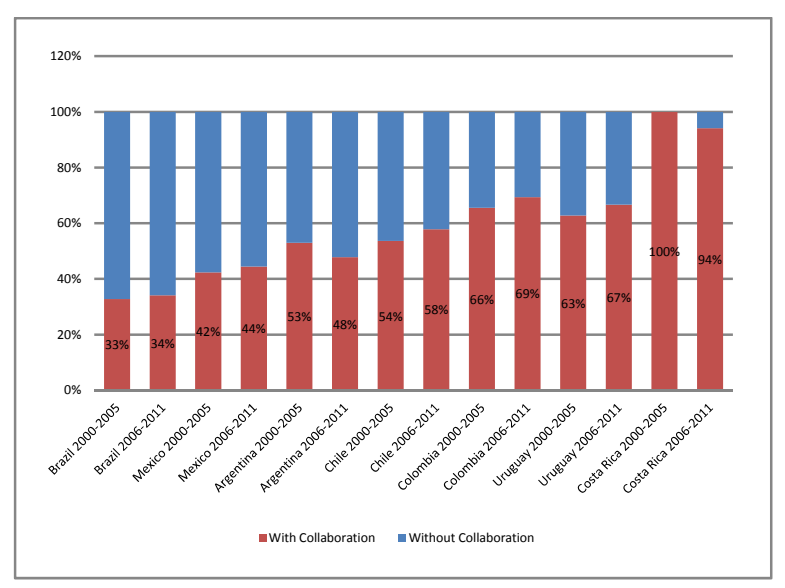

Figure 6. Amount of collaboration in ISI publications 
Figure 6 shows that, on the average, $40 \%$ of the LAC publications are done in an international collaboration context. Note that we do not include here the collaboration that occurs among researchers from the same country.

Looking now into the specific countries participating in each collaborative publication, we discovered that most collaboration goes with USA and European Countries. Just $7.46 \%$ of the collaboration (in written papers) involves just LAC countries.

This lack of regional collaboration does not come as a surprise and it can be explained by several reasons. For instance, it is easier to obtain grants and resources for research endeavors with USA or Europe; it is also easier for LAC researchers to continue working with their former advisors abroad (if they happen to return to their home countries after completing their graduate studies abroad). Moreover, we believe that another important cause for this situation is the lack of visibility that LAC researchers (and their contributions) have within the region.

The LACCIR initiative is a serious attempt to foster collaboration among research groups of the LAC region in order to overcome the critical mass effect syndrome and thus improve research contributions and increase technology transfer to the local economies. It is interesting to notice in Figure 6 that there is a relative increase (2006-2011 compared to 2000-2005) in the percentage of collaboration in most of the analyzed LAC countries. We do not claim that it is due to LACCIR's efforts, but we do expect that we can contribute to extended collaboration in the long range. In the next section we describe the organization and the main activities of the LACCIR federation.

\section{The LACCIR Federation}

The LACCIR Federation was brought to life in May 2007 as a joint effort among LAC universities, private organizations and public agencies, following an international request for proposals from Microsoft Research (MSR). The main goal was to implement several programs (and obtain the appropriate resources), intended to improve the collaboration in ICT research in the region and thus increase research opportunities for faculty and graduate students in a collaborative environment.

LACCIR was envisioned to provide LAC research centers with specific resources and a virtual collaborative environment to promote cross-country research, education solutions and technology transfer from universities to the local economies.

LACCIR programs are currently being funded by Microsoft Research (MSR) and the Inter American Development Bank (IADB); also, they are supported by the Organization of American States (OAS). Additionally, CONACYT (Ministry of Science \&
Technology in Mexico) provides matching funds for LACCIR collaborative research activities with Mexican research centers. Next we present a brief description of the structure, governability and main activities of LACCIR.

\subsection{Structure and Governability}

The LACCIR organization follows a "Hub and Spokes" structure, where the Hub agency is in charge of designing and administering the collaboration programs. Such role is performed jointly by Catholic University of Chile (UC-Chile) and University of Chile (U-Chile).

The "Spoke" organizations were selected among the most prestigious LAC universities, in term of research in Computer Science, and include Monterrey Institute of Technology (ITESM) and National Polytechnic Institute (IPN) from Mexico; University of the Republic, Uruguay; University of Buenos Aires, Argentina; University of Costa Rica, University of West Indies from the Caribbean, Los Andes University from Colombia, and ESPOL University from Ecuador. The Spoke and Hub universities cover a wide geographical area of the LAC region.

The spoke universities support the Hub in several collaborative initiatives, e.g. applying for matching funds at local funding agencies, participating in joint research projects, building collaboration networks and disseminating Request for Proposals in their area of influence. They also participate in the "LAC research observatory", gathering information about local ICT researchers, on-going projects and research institutions.

LACCIR is governed by an international Joint Steering Committee (JSC) and an Advisory Board Committee (ABC). The JSC includes representatives from each stakeholder (MSR, IADB and OAS and the Hub universities) and oversees the strategies and activities of LACCIR. The advisory board has a representative from each spoke institution and the Hub. The JSC and the ABC define the long-term goals and strategies for LACCIR.

Other partner institutions collaborate with LACCIR in different ways such as looking for matching funds for research initiatives financed by LACCIR, organizing joint RFPs, joint conferences and seminars, providing networking and computing infrastructure, and management of virtual communities and educational networks.

\subsection{Main Activities}

There are three LACCIR programs that are currently promoting collaborative ICT research activities in the region; these are: (1) RFPs for Collaborative ICT Research Projects, (2) RFPs for Short Stays Program and (3) an ICT Research 
Observatory for the region. Each of these programs is briefly explained below.

1. RFPs for Collaborative ICT Research Projects. Once a year, LACCIR opens a Request for Proposals (RFP) for applied research projects on ICT. Projects are implemented in a one year execution period and proposals are evaluated by three independent experts of the LACCIR technical committee. This committee is currently composed by nearly 200 prestigious ICT researchers world-wide. The evaluation score determines which project must be funded. Typically between 5 and 8 projects are funded per year, and each one receives 50,000 USD approximately (in addition to in-kind resources provided by participant institutions). For the purpose of fostering collaboration, projects must include researchers from at least two institutions belonging to different LAC countries. The application areas for these projects are those relevant for the region, including: education, healthcare, micro-economies, energy, environment and e-Government. Up to now, there have been five annual RFP processes, in which more than 600 researchers have participated, from 50 universities of 19 LAC countries, resulting in 26 funded projects.

2. The Short Stays Program. Similarly to the RFPs for research project, LACCIR assigns small grants, through its Short Stays Program (SSP) to encourage graduate ICT students mobility and faculty exchanges within the region. The goal is to increase collaboration among research groups in the region by means of short research visits of graduate (M.Sc. and Ph.D.) students to schools from different LAC countries. It typically produces long standing links between research teams, increasing the shared research efforts in the region. Considering the 2011 SSP process, LACCIR has provided SSP grants (each grant in the order of $\$ 5,000$ dollars) to 35 graduate students up to now. Additionally, LACCIR seeks collaboration with other institutions to promote graduate students mobility and supports Microsoft Research in its process of awarding research Internships at the Redmond Lab and Doctoral Fellowships in the region. CONACYT, the National Research Agency in Mexico, has given LACCIR a number of scholarships to be used by LAC graduate students that want to perform research visits in Mexican universities.

3. The ICT Research Observatory. LACCIR is building a web-based ICT research map of the region with the objective of providing a collaborative space where LAC students, researchers and other interested parties can place and find information about on-going projects, technical reports, active researchers, resources, sources of funding, graduate programs, and opportunities for cooperation among academia, industry, government and others to foster applied research, technology transfer and innovation in the region. LACCIR maintains an up-to-date repository of studies and reports about the evolution of ICT research and development in the region.

In addition to the three previously mentioned programs, LACCIR provides Web-based ICT resources to students and researchers participating in collaborative projects. These include virtual research environments, e-learning courses, distributed seminars, video-conferences, and distance graduate thesis defenses. It facilitates communication and partnership across the region.

Moreover, LACCIR delivers some resources to the Spoke Universities to be used in-campus to promote the interactions not only among members of the LACCIR Virtual Community, but also among members of several research communities in the region. In order to do that, each Spoke University provides a virtual conference room for these activities and develops, maintains, and continually enhances a Web presence, contents and a research virtual community localized in the LACCIR portal. Several Microsoft software tools are available for free to support and enhance collaboration among these researchers.

\subsection{Networking with Other Research Promotion Agencies}

As was mentioned before, several partner institutions collaborate with LACCIR in different ways and through several programs. Some of the most well-known partners institutions are the following ones: National Science Foundation (USA), the Inter-American Institute for Global Change Research (Brazil) and the Sao Paulo state research foundation FAPESP (Brazil). There are also particular governmental agencies for research support and promotion acting as partners, such as COLCIENCIAS in Colombia, CONACYT in Mexico and CONICYT in Chile. These institutions typically support particular activities that are performed through the LACCIR regular programs.

\section{Collaborative ICT Research Projects}

As mentioned before, twenty eight collaborative ICT research project have been funded by LACCIR in the first five years of operations. Twenty two projects were funded in the 2007-2010 period, and five new grants were awarded in the 2011 LACCIR 
RFP process. These last projects have started operations during the first term of 2012.

Table 2 presents the statistics for each RFP process; for example the number of proposals received, the number of participating researchers, the number of universities involved and the number of projects selected for funding. Considering these statistics we can conclude that LACCIR RFPs represent an important call among researchers of the LAC region, and also that they help increase the amount of collaboration in the region.

Table 2. LACCIR RFP Processes

\begin{tabular}{|c|c|c|c|c|}
\hline $\begin{array}{c}\text { LACCIR } \\
\text { RFP } \\
\text { Process }\end{array}$ & $\begin{array}{c}\text { Proposals } \\
\text { Received }\end{array}$ & $\begin{array}{c}\text { Participating } \\
\text { Researchers }\end{array}$ & $\begin{array}{c}\text { Universities } \\
\text { Involved }\end{array}$ & $\begin{array}{c}\text { Projects } \\
\text { Selected }\end{array}$ \\
\hline 2007 & 23 & 105 & 29 & 5 \\
\hline 2008 & 36 & 163 & 50 & 5 \\
\hline 2009 & 25 & 142 & 50 & 5 \\
\hline 2010 & 22 & 103 & 39 & 6 \\
\hline 2011 & 32 & 129 & 49 & 5 \\
\hline Total & $\mathbf{1 3 8}$ & $\mathbf{6 4 2}$ & $\mathbf{2 1 7}$ & $\mathbf{2 6}$ \\
\hline
\end{tabular}

Table 3 provides some basic figures solely considering those funded projects that have already finalized. These results show an important number of journal and conference publications in almost all the areas considered in the RFPs.

Table 3. Finalized Projects

\begin{tabular}{|l|c|c|c|c|c|}
\hline $\begin{array}{c}\text { Project } \\
\text { ID }\end{array}$ & $\begin{array}{c}\text { Application } \\
\text { Area }\end{array}$ & Countries & $\begin{array}{c}\# \\
\text { Researchers }\end{array}$ & $\begin{array}{c}\text { \# Journal } \\
\text { Articles }\end{array}$ & $\begin{array}{c}\text { \# Conf. } \\
\text { Articles }\end{array}$ \\
\hline $2007 / 1$ & Education & $\begin{array}{c}\text { Chile, } \\
\text { Colombia }\end{array}$ & 8 & 2 & 14 \\
\hline $2007 / 2$ & Education & $\begin{array}{c}\text { Uruguay, } \\
\text { Argentina, } \\
\text { Ecuador }\end{array}$ & 11 & 3 & 33 \\
\hline $2007 / 4$ & $\begin{array}{c}\text { Micro- } \\
\text { Economies }\end{array}$ & $\begin{array}{c}\text { Chile, } \\
\text { Mexico }\end{array}$ & 3 & 2 & 4 \\
\hline $2007 / 5$ & Healthcare & $\begin{array}{c}\text { Mexico, } \\
\text { Chile }\end{array}$ & 5 & 3 & 5 \\
\hline $2008 / 1$ & $\begin{array}{c}\text { Environment } \\
\text { \& Climate } \\
\text { Change }\end{array}$ & $\begin{array}{c}\text { Uruguay, } \\
\text { Brazil }\end{array}$ & 7 & 0 & 3 \\
\hline $2008 / 2$ & E-Government & $\begin{array}{c}\text { Brazil, } \\
\text { Chile }\end{array}$ & 2 & 0 & 1 \\
\hline $2008 / 3$ & $\begin{array}{c}\text { Micro- } \\
\text { Economies }\end{array}$ & $\begin{array}{c}\text { Argentina, } \\
\text { Uruguay }\end{array}$ & 6 & 1 & 9 \\
\hline $2008 / 4$ & E-Government & $\begin{array}{c}\text { Mexico, } \\
\text { Brazil, } \\
\text { Uruguay }\end{array}$ & 6 & 1 & 5 \\
\hline $2008 / 5$ & $\begin{array}{c}\text { Micro- } \\
\text { Economies }\end{array}$ & $\begin{array}{c}\text { Chile, } \\
\text { Mexico }\end{array}$ & 3 & 2 & 5 \\
\hline Total & $\mathbf{5}$ areas & 7 countries & $\mathbf{6 7}$ & $\mathbf{1 9}$ & $\mathbf{8 7}$ \\
\hline
\end{tabular}

Table 4 summarizes total numbers for all the projects funded by LACCIR from 2007 to 2012 (first term), grouped by application area. These numbers show an increased amount of collaboration and visibility of the ICT applied research in the region, and LACCIR is clearly contributing in this direction. The expected publications for the 2007-2012 period include conference and journal papers, and it represents an interesting outcome for LACCIR.
Table 4. 2007-2012 LACCIR RFP Projects

\begin{tabular}{|l|c|c|c|c|}
\hline $\begin{array}{c}\text { Application } \\
\text { Area }\end{array}$ & $\begin{array}{c}\# \\
\text { Projects }\end{array}$ & $\begin{array}{c}\text { \# Involved } \\
\text { Countries }\end{array}$ & $\begin{array}{c}\text { \# Involved } \\
\text { Researchers }\end{array}$ & $\begin{array}{c}\# \\
\text { Expected } \\
\text { Publicati } \\
\text { ons }\end{array}$ \\
\hline Education & 6 & 9 & 40 & 82 \\
\hline HealthCare & 6 & 7 & 34 & 41 \\
\hline M-Economies & 4 & 5 & 18 & 36 \\
\hline Energy & 0 & 0 & 0 & 0 \\
\hline Environment & 8 & 7 & 34 & 25 \\
\hline E-Government & 4 & 5 & 26 & 38 \\
\hline TOTAL & $\mathbf{2 8}$ & $\mathbf{3 3}$ & $\mathbf{1 5 2}$ & $\mathbf{2 2 2}$ \\
\hline
\end{tabular}

In the next sections we describe some selected projects as a way of illustrating the depth and extension of the LACCIR initiative.

\subsection{ICT Projects Applied to Education}

This section describes four ICT research initiatives applied to education scenarios. These initiatives exemplify the work that LATAM researchers are doing in this area under the support of LACCIR.

4.1.1. A Digital Workbook Tool to Support Asynchronous Collaboration. In this project, students and instructors can make annotations on a presentation (or any other type of document) using different tools running on a Tablet PC. However, such tools are not able to manage the annotations as an independent information layer that can be shared or integrated with annotations made by other students. For example, a student "A" who was not able to attend today's lesson, could request and integrate the annotations done by three of his/her partners " $B$ ", "C" and " $D$ " during the presentation in order to improve his/her understanding of specific issues. All of them are using a digital workbook able to share objects and keep the link among them.

The main goal of this research project is to develop a digital workbook able to run on Tablet PCs, which allows engineering instructors and students to share several kinds of objects. These objects can be, for example, a Word document, or an annotation included inside a document. In addition, special functionality will be developed to integrate this digital workbook to the Conference XP Platform. It will be used not only to support traditional (synchronous and face-to-face) instruction, but also e-Learning and b-Learning [13, $14]$.

4.1.2. JARDIN: Just an Assistant for Instructional Design. The concept of Learning Objects has evolved from the need to technically standardize and reuse learning materials. They 
provide economic advantages over traditional content creation. For example, high quality interactive multimedia could be reused in several courses, compensating the cost of production; individualized learning could be possible, as the most relevant/appropriate learning material could be selected for each student based on their learning preferences; teachers could concentrate in create meaningful learning paths instead of recreating the content. As favorable as they seem for education, Learning Object technologies has not crossed the chasm between early adopters and mainstream use. The main reasons for its lack of acceptance by common teachers is the level of effort required to create, describe, search and re-use Learning Objects with the current generation of tools.

This project creates an Instructional Design Assistant that helps the teacher to assemble learning objects and highlights the relevant learning objects according with the student's learning preferences $[15,16]$.

4.1.3. Bridging the Gap between Mobile and InClassroom Learning. Increasing the quality of education has often been cited as one of the most important, if not the most important way how LatinAmerican countries can reduce the gap with fully developed countries. In many countries there have been important governmental initiatives aimed to introducing computer technology at schools in order to support more effective teaching/learning practices as well as introducing the students to the technological world, including the internet. The fast development of mobile computing combined with access to content almost everywhere and every time, allows learners to gain new experiences regarding learning in a variety of situations and not only in school settings. This is known as pervasive learning. These technologies give new opportunities for designing innovative educational activities that can be carried out anywhere. The design of such activities is especially challenging when it comes to conceptualizing how pervasive technologies can support collaborative knowledge building $[17,18]$.

However, the expected goal that new technologies will transform learning practices has not yet been fully realized, especially if it's taken into account what has been going on in computer supported collaborative learning. Context-aware systems are those capable of adapting their operations to the current context without explicit intervention of the user.

4.1.4. Latin American Network to Support Collaborative Education on Experimental Software Engineering. Instruction in software engineering has been widely recognized as a key knowledge domain for students of computer science and informatics. An instructional strategy that involves practical experiences is fundamental to acquire the knowledge involved in this discipline. Typically, these practical experiences are carried out in teams as a way to keep the similarity with a real software development scenario. There, students have to learn how to keep the communication, coordination and collaboration inside the group in order to reach a common goal. This common goal could be to obtain a requirements specification, a product design or an implemented software solution.

Teamwork is a mechanism that allows undergraduate and graduate students to gain experience in building software. Teamwork activities should be complemented with contemporary trends imposed by the software industry; for example the globalization and market opening. Software engineers are pushed to overcome language, time and location barriers to be part of software development team.

This project implements a set of distributed collaborative instructional activities to enhance the teaching-learning processes in software engineering courses $[19,20]$.

\subsection{ICT Projects Applied to Healthcare}

This section describes a research initiative applied to healthcare, which is the most representative one funded by LACCIR.

4.2.1. Smart Phones and Ambient Displays to Support Collaboration in Hospital Work. This project develops a collaborative environment that assembles a set of devices - particularly smart phones and ambient displays- and electronic services that augment informal co-located collaboration in hospitals while users are on-the-move [21, 22].

Hospital work is characterized by the need for coordination and collaboration among specialists with different areas of expertise, an intense information exchange, the integration of data from many devices or artifacts and the mobility of hospital staff, patients, documents, and equipment. At the same time, this working environment is highly critical and prone to error.

In hospitals, informal communication is an essential resource for supporting coordinated medical tasks, to discuss diagnosis and/or treatments of patients and to gather the artifacts and human resources necessary for patient care. Hospital staff spends $53 \%$ of their time out of their base location.

\subsection{ICT Projects Applied to E-Government}

This section presents two ICT research initiatives applied to e-Government scenarios.

4.3.1. Collaborating in Disaster Relief Efforts. The Latin American and Caribbean (LAC) region is 
especially subject to natural disasters such as earthquakes (from Mexico to Chile), hurricanes (Caribbean), and floods (coastal areas), besides mancaused catastrophes, e.g., chemical spills and forest and urban fires. Coping with large disastrous events requires cooperation by people from several organizations, including firemen, police, local and national Government personnel (especially, engineers), Red Cross, hospital personnel and Armed Forces personnel. The coordination in such cases becomes a critical aspect of the relief effort. This gets very complicated due to the very different information systems used by these organizations.

The specific goal of this project is to generate IT solutions for: helping firefighters to get to the disaster area in minimum time by giving online advice to the drivers; briefing firefighters with relevant information from the event during their moving to the disaster area; coordinating firefighters' activities when a disaster has occurred; providing firemen with awareness of the available physical resources, and managing their sharing; and supporting firemen's decision making [23, 24].

4.3.2. E-CLOUDSS: Building E-Government Clouds using Distributed Semantic Services. The objective of E-CLOUDSS is to build an infrastructure for mashing up reliable semantic services for building e-government clouds. "Mashups" represent a new wave for building Web applications. A mashup is an application that presents content available from different sources by reusing the contents provided by third parties (e.g. Web pages, Web services).

A service is an autonomous software that offers some functionality through a network. E-CLOUDS focuses on reliability of mashed up systems represented as non-functional properties that describe how the execution must be done with respect to some observable attributes. Such properties conduct to build reliable mashups. Although numerous systems, models and languages have been proposed for supporting non-functional properties, they are ad-hoc solutions that weave application logic with nonfunctional properties. This situation results in mashup services that are difficult to evolve and to maintain $[25,26]$.

\subsection{ICT Projects Applied to Micro- Economies}

This section describes two ICT research initiatives applied to Micro-economies scenarios.

4.4.1. A Real Time System Based on Computer Vision Techniques to Supervise and Allocate Cash Registers at Grocery Stores. The retail industry in the LAC region has shown a notable development in the last decades, especially in Chile and Mexico. The great expansion and need for high technological standards makes this sector a good target to develop sustainable technological developments in Latin America. This project focuses on this industry by proposing the development of computer vision based technology to improve the level of service at checkout lines in grocery stores.

This is a highly relevant task for grocery stores because it directly affects customer service perception, a key element for the success of a service company. Furthermore, the allocation of cash registers is one of the main factors in the cost of providing service. If cash registers average utilization is low, that suggests the waiting line design is inefficient. Poor system design can result in over staffing. On the other hand, long waiting times suggest a lack of concern by the company or can be viewed as a perception of poor service quality.

This project aims to develop a system to solve the supervision and allocation of cash registers in grocery stores. The proposed application uses computer vision technology to continually measure relevant parameters related to the level of service at checkout lines, such as waiting times, attention times, and number of incidents that cause delays [27, 28].

4.4.2. Low Cost Computer based System for Quality Evaluation and Preservation of Grains Stored in polymer Bags. Grain growers in Latin America are concerned on how to ensure the quality and safety of the storage method for their crops. This concern is derived from the fact that the storage conditions strongly influence both the quality of the food that people consume and the profits that growers can obtain from their production.

A great expansion is observed in Argentina, Uruguay and Chile of an ad-hoc low-cost storage technique named "harvest bags" that consists in keeping the grains into hermetic polyethylene bags which are stored in the same field of crop. The benefits attributed to the harvest bag system include: low capital cost storage system; improved harvest logistics and associated cost savings; and easily expanded storage capacity to accommodate crop size variations.

This project aims to design and implement an intelligent system for monitoring and automatically adapting the internal conditions of the grain stored into harvest bags, in order to improve their preservation state [29].

\subsection{ICT Projects Applied to Earth, Environment and Climate Change}

Next we describe two ICT research initiatives applied to earth, environment and climate change. 
4.5.1. Domestic Environment Monitoring with Opportunistic Sensor networks (DEMOS). In developing countries, environmental hazards and pollution are major contributors to childhood deaths and illnesses. The objective of this project is to design, develop and deploy a cheap network of sensors and other necessary means to monitor, aggregate and communicate the environmental parameters of the habitat of the children at the environmentally vulnerable neighborhoods. Those sensors should be designed to be deployed inside houses, at schools or outside, at parks or other public places which are visited by the most environmentally vulnerable children during their daily life. This provides a wide platform for opportunistic networking applications.

The basic idea behind opportunistic networking is that, in the absence of a fixed infrastructure for connectivity, content of interest could be transferred between mobile devices using the connection "opportunities" that arise whenever the mobile device comes into wireless range of other wireless devices [30].

\subsubsection{Integrating MS Live Earth, Max Ent and Presence into a interconnectivity platform to assist wildlife conservation in the Andes of Chile and Bolivia (LiveANDES). Wildlife Conservation in the Andes is an urgent priority, as endangered endemic species compete for limited suitable habitat with human development, in a context of changing climate. Agriculture activities collide with wildlife conservation interests as predators such as pumas, and culpeo foxes prey on livestock. Wildlife officers confront information management challenges on a day-to-day basis. There is a need to improve the capacity of wildlife managers to manage and analyze this spatial information in the form of simple but powerful tools for mapping multi-contextual field data.}

MS Live Earth provides imagery that allows local agencies to locate livestock-raising operations, protected reserves, wildlife presence and distribution and basic ecological features of the landscape in a free, Web-based environment, potentially allowing anyone, anywhere, to access information and take management decisions. An Andean Wildlife Decision-Support Platform called LiveANDES (Advanced Network for Distributions of Endangered Species) will be developed by using and combining information from: MS Live Earth, Maxent (predicts which areas within the region satisfy the requirements of the species' ecological niche), Presence (Estimates of the occupancy rates of elusive wildlife) \& GIS (Geographic Information Systems) software and local databases [31].

\section{Related Work}

Borges and Pino [2] have reviewed previous collaboration efforts in Latin America, identifying successes and failures. They also proposed a framework, the CA/CR graphs, to evaluate the collaboration initiatives. If we would apply this framework to LACCIR, we would find the following results: (1) it would score high in four of the six dimensions of actions: mobility of faculty members and students, development of research/industrial projects, dissemination of information, and interchange of students; and (2) it would score moderately in the other two dimensions: organization of courses and organization/participation of scientific events.

To the best of our knowledge, there are no other initiatives trying to promote and measure the collaborative research in ICT in the region. It provides an interesting opportunity to LACCIR.

The LACCIR initiative is still too young in order to study the real impact of its actions in the region. However, it is possible to observe that it is already scoring well for scientific publications, theses, industrial projects and didactic materials.

We have used publications data from ThomsonReuters ISI. It should be noted that this data may be incomplete. A recent article by Wainer et al. [8] has suggested the existence of "invisible research" which is not reported by indexed publications. This situation is particularly acute in Computer Science, since some meaningful research results are not published in journals, but presented at well-ranked conferences instead.

\section{Conclusions and Future Actions}

If we look into general indicators related to ICT usage and innovation, we can see that the LAC region is definitely lagging behind the developed world. For instance, in the last report from the World Economic Forum [9] it is shown that, in terms of ICT usage, only a few LAC country are positioned among the top 50 (Chile is 39, Uruguay 45, Costa Rica 46, Mexico 78, and Argentina 96). In the top 20 of this report we can find Sweden, Singapore, Finland, Denmark and Norway, but no LAC countries.

We strongly believe that the LACCIR initiative can bring sustainable improvement to these indicators and thus contribute to the social development of the region. The LACCIR endeavor is a serious attempt to foster collaboration among LAC research groups in order to overcome the critical mass effect syndrome and thus improve research contributions and technology transfer to the local economies $[1,7]$.

The LACCIR federation is also addressing this challenge through a public Web directory of LAC researchers in ICT, where anybody can identify possible regional partners to conduct a specific 
research work. It allows searches by keywords and by interest areas. Currently, the LACCIR directory includes more than 750 ICT active researchers in the region. In the mean time, we are performing a massive data collection process to create a directory of LAC ICT researchers as complete and updated as possible.

\section{Acknowledgments}

This work has been supported in part by the InterAmerican Development Bank under Grants ATN/SF10807-RG, ATN/KF-11755-RG and by Microsoft Research MoU of May 2007 and May 2010.

\section{References}

[1] P. Ariztía, P. "ICT Advancements in Latin America and the Caribbean". School of Engineering undergraduate thesis, Pontificia Universidad Católica de Chile, 2009.

[2] M.R.S. Borges, J.A. Pino, "Information Technology in Latin America: Two decades of collaboration". Information Technology for Development 9 (3,4), pp. 189-204, 2000.

[3] ISI Web of Knowledge (s.f.). Web site: http://isiknowledge.com/ (Access Date: 27 Sept., 2012).

[4] L. Leydesdorff, I., "A Global Map of Science Based on the ISI Subject Categories". Journal of the American Society for Information Science and Technology, October 18, 2008.

[5] Organization of American States. "Action plans on ICT Development”. Science \& technology ministers meetings; Peru, 2004.

[6] Organization of American States. "Action plans on ICT Development”. Science \& technology ministers meetings; Mexico, 2008.

[7] T. Ulloa, "Research and Development with ICT: Methodology and indicators analysis at LACCIR Virtual Institute”. Computer Engineering thesis, Pontificia Universidad Católica de Chile, 2009.

[8] J. Wainer, S. Goldenstein, C. Billa, "Invisible Work in Standard Bibliometric Evaluation of Computer Science". Communications of the ACM 54(5), 141-146, 2011.

[9] World Economic Forum "The Global Information Technology Report 2010-2011”, 2011.

[10] The LACCIR Virtual Institute Web site. http://www.laccir.org/ (Access Date: 27 Sept., 2012).

[11] World Bank Web Site. http://data.worldbank.org/_ (Access Date: 21 May, 2012).

[12] The World Fact Book Web site. https://www.cia.gov/theworld-fact-book (Access Date: 27 Sept., 2012).

[13] I. Claros, C. Collazos, R. Cobos. "Awareness Services to improve the education scenario supported by KnowCat". System and Information Advances Journal, 127-133. June 2009.

[14] J. Gallardo, A. Molina, C. Bravo, M. Redondo, C. Collazos. "Empirical and heuristic-based evaluation of collaborative modeling systems: an evaluation framework, Group Decision and Negotiation”. Lecture Notes in Computer Science, Vol. 5411, pp.340-355, 2009.

[15] X. Ochoa, "Modeling the Macro-Behaviour of Learning Object Repositories”. LACLO 2010, Sao Paulo, Brazil, Sept. 2010.

[16] C. Badell, Motz, R. Sum. "Extraction of learning objects with pedagogical design meta-data”. CCITA 2009 Congress, IEEE TICAI Education Society, Spanish Chapter. 2009.

[17] N. Baloian, G., Zurita, J. Pino. (2010). "The Role of Patterns in Networked Collaborative Learning Environments". Journal of Network and Computer Applications.

[18] B. Weyers, W. Luther, N. Baloian, N. (2011). "Interface creation and redesign techniques in collaborative learning scenarios”. Future Generation Computer Systems, 127-138.

[19] F.D. Giraldo, S.F. Ochoa, L. Aballay, C. Clifton, A. Neyem, R. Anaya. "Instructional Software Engineering Activities Using CODILA: Some Latin American Experiences". Proc. International Conference on Education and Educational Technology (EET), China, 2011.

[20] F.D. Giraldo, S.F. Ochoa, M. Herrera, A. Neyem, J.L. Arciniegas, C. Clifton, S. Zapata, F. Lizano. "Applying a distributed CSCL activity for teaching software Architecture". Proc. International Conference on Information Society (i-Society), IEEE CS Press UK, 2011.

[21] A. Mejía, J. Favela, A. Moran. "Understanding and Supporting Lightweight Communication in Hospital Work". IEEE Trans. on Information Technology in BioMedicine, 140-146. 2010.

[22] J. Rodriguez-Covili, S. Ochoa, J. Pino, J. Favela, D. Mejia, A. Moran. Towards a reference architecture for the design of mobile shared workspaces. Future Generation Computer Systems Journal, 109-118. 2011.

[23] P. Antunes, V. Herskovic, S. Ochoa, J. Pino. "Structuring Dimensions for Collaborative Systems Evaluation”. ACM Computing Surveys, 44(2), February 2012.

[24] R. Escalfoni, V. Braganholo, M. Borges. "A method for capturing innovation features using group storytelling”. Expert Systems with Applications, 1148-1159, 2011.

[25] G. Montiel-Moreno, J. Zechinelli-Martini, G. Vargas-Solar. "Loose integration of views based on recall and precision". Journal of Inteligencia Artificial, 2010.

[26] U. Souza da Costa, A. Martins-Moreira, M. Musicante, P. Souza Neto. "JCML: A Specification Language for the Runtime Verification of Java Card Programs”. Science of Computer Programming Journal 2010.

[27] D. Maturana, D. Mery, A. Soto. "Learning Discriminative Local Binary Patterns for Face Recognition". Proceedings of the Ninth IEEE International Conference on Automatic Face and Gesture Recognition 2011.

[28] P. Cortez, D. Mery, E. Sucar. "Object Tracking based on Covariance Descriptors and an On-Line Naive Bayes Nearest Neighbor Classifier" In Proceedings of 4th PacificRim Symposium on Image and Video Technology (PSIVT2010), pp. 139-144, IEEE Computer Society, Singapore, Nov.14-17, 2010.

[29] J. Irazábal, C. Pons, C. Neil. "Model Transformation as a Mechanism for the Implementation of Domain Specific Transformation Languages". Electronic Journal of SADIO. (n.d.) 
International Journal for e-Learning Security (IJeLS), Volume 2, Issue 1, March 2012

[30] J. Visca, J. Baliosian, E. Grampin. "A distributed Notification Bus for constrained devices". IEEE/IFIP 6th Latin American Network Operations and Management Symposium, October, 2009.

[31] C. Bonacic, M. Miranda, L. Pacheco, G. Ceballos, A. Neyem. "Live Andes - A platform to assist wildlife conservation in the Andes". Microsoft Research Faculty Summit, Cartagena, Colombia. 2011. 